\title{
Influence of (extreme) radiation and optical characteristics in physical and biological features of a regulated lake.
}

\author{
Lien Rodríguez-López ${ }^{1,1}$, Oscar Parra ${ }^{1}$, Rolando Cárdenas ${ }^{2}$, Lisdelys González ${ }^{4}$, Pablo \\ Pedreros ${ }^{1}$, Bernhard Karrasch ${ }^{3}$, Viviana Almanza ${ }^{1}$, and Roberto Urrutia ${ }^{1}$ \\ ${ }^{1}$ University of Concepción, Environmental Sciences Center (EULA). Chile \\ ${ }^{2}$ Planetary Science Laboratory, Universidad Central "Marta Abreu" de Las Villas, Santa Clara, Cuba \\ ${ }^{3}$ UFZ - Helmholtz Centre for Environmental Research, Brückstraße 3a, D-39114 Magdeburg, \\ Germany \\ ${ }^{4}$ University of Concepción, Faculty of Engineering. Chile.
}

\begin{abstract}
Radiation plays an essential role in the establishment and proliferation of biota in natural environments. The photosynthetic process determines the existence of all life forms, since it supplies the energy that this photobiological process needs for the reaction, it is carried out by absorbing photons in the visible and infrared bands of the electromagnetic spectrum, while ultraviolet (UV) photons and ionizing radiation tends to inhibit it (decreasing, by various mechanisms, its quantum yield). The speed of photosynthesis, measured by the amount of $\mathrm{O}_{2}$ released in the unit of time (or $\mathrm{CO}_{2}$ absorbed) depends on the intensity of the incident light, in the last three decades this radiation has been increased by the decrease of stratospheric ozone in the South latitudes of our planet, for this reason the UV values in the aquatic ecosystems of Chile have been high as well as a considerable increase in the surface temperature of the bodies of water, having possible implications in the primary biological productivity of the ecosystems lakes, especially in Andean lakes. This increase in radiation could be related to the abundance of the different algal groups and the seasonal variability of them, creating favorable conditions for those dominant species considered invasive of these ecosystems. This paper shows the direct relationship between the concentration of ozone $\left(\mathrm{O}_{3}\right)$ and ultraviolet radiation and how it influences the vertical distribution of the phytoplankton groups in the water column. For the first time it was found in this lake the appearance of a bloom of toxic cyanobacteria.
\end{abstract}

\section{Introduction}

The decline of stratospheric ozone $\left(\mathrm{O}_{3}\right)$ in the 1970 became one of the main global problems [1]. In addition to this global decrease, must be added, another phenomenon known as $\mathrm{AOH}$ (Antarctic Ozone Hole) originates in spring at the South Pole. In this case,

1 Corresponding author: 1rodriguezl@udec.cl 
when the concentration of $\mathrm{O}_{3}$ decreases considerably in the Antarctic stratosphere, associated with the activity of the Antarctic Polar Vortex, it causes alterations in the natural cycle of $\mathrm{O}_{3}$ and thereby increases the levels of ultraviolet (UV) radiation that reach superficial level of water bodies and before they were absorbed by this gas. Although the levels of $\mathrm{O}_{3}$ have increased in recent years and the layer has been regenerated, the initial values of this gas have not been recovered before the beginning of the decline in 1970 . Therefore, it is considered a threat to the nearby latitudes [2]. Therefore, the UV radiation reaching the surface water level has increased; therefore, the southern hemisphere has received more radiation than the northern hemisphere in the last three decades [3]. Within the Southern Hemisphere, Chile, due to its physics-geographic characteristics, presents extreme radiation conditions, resulting in a unique experimental scenario to demonstrate what this increase would mean for water ecosystems and aquatic organisms.

In this sense, in lakes of height altitude than 1000 m.a.s.l. the incident UV radiation is increased by $10 \%$, [4]. If we add to that, that water body presents characteristics of an oligotrophic system (very transparent waters), the propagation of the incident radiation in the water column could mean considerable influence or damage in the phytoplankton groups that coexist despite these conditions. In the literature numerous and diverse damages by UV radiation on this community have been reported [5], being the base link of the trophic chains, i.e., phytoplankton the most vulnerable to the increase of the dose of irradiation, since it is dependent on the light for the realization of one of its fundamental processes: photosynthesis and UV radiation has been reported as the cause of the inhibition of this process [6]. Higher-frame organisms have a greater capacity to generate structures to avoid the damage caused by exposure to UV radiation, but they do not escape their harmful effects. In some aquatic vertebrates, such as fish, damage caused by UV radiation has also been described when cataracts are detected in the eyes of some fishes [5]. In addition, sunburns have been identified in the skin, common in high mountain fishes, when exposed, due to altitude, to higher values of incident UV radiation [7]. However, in the case of phytoplankton of freshwater systems studies have been limited, and have reported losses in the primary daily production depending on the UV range since insignificant $(2.5 \%)$ up to appreciable (26\%) [1].

Therefore, these new changing environmental conditions have allowed some species to develop defense mechanisms (photo protection) to minimize the harmful effects of UV radiation. However, the new mechanisms only represent an effective filter against certain exposure doses and radiation levels, which could mean that some groups are favored to the new habitat conditions, prevailing those that have been better adapted to these changes.

\section{Material and Methods}

\subsection{Study Area}

Laja Lake is located at $36^{\circ} 54$ 'South latitude and $71^{\circ} 05^{\prime}$ ' West longitude in the Andean mountain range (Central Chile). It has an altitude of 1360 m.a.s.l., is the largest natural reservoir in Chile with 7500 million $\mathrm{m}^{3}$. Its formation took place by the successive actions of glaciers and volcanoes. The Laja Lake basin is formed by an elongated river (Laja River) with a valley of lateral tributaries, drowned by a lava dam built during an eruption episode of the Antuco Volcano[8]. The climate of the area corresponds to a Mediterranean climate, with six mild-dry months and six cold-humid months, degrading to cold climate over 1500 $\mathrm{m}$ of altitude. Regarding temperatures, the lower annual average corresponds to $10^{\circ} \mathrm{C}$, while the monthly average of July is $6^{\circ} \mathrm{C}$ and in January it reaches $15^{\circ} \mathrm{C}$, maintaining a notable decrease of this one with altitude [9]. Due to the altitude, this lake is subjected to strong 
winds, pronounced temperature, variable during the day and strong solar radiation and therefore UV Radiation [10]. The hydrological characteristics are an average annual rainfall of about $2170 \mathrm{~mm}$, generally in the form of snow, with a maximum length of $35 \mathrm{~km}$ and 7 $\mathrm{km}$ in width [11] a surface area up to $87 \mathrm{~km}^{2}$, with depth maximum of $134 \mathrm{~m}$ (average depth $54 \mathrm{~m}$ ). The lake level varies throughout the year, from 15 to $40 \mathrm{~m}$, the lowest level occurs in the autumn before the first rains and the highest in spring during the thaw [12]. The lower volume is caused by the intensive use of water from three hydroelectric power plants (Antuco, Abanico and El Toro), generating approximately $300 \mathrm{MW}$ [13] and irrigation canals.

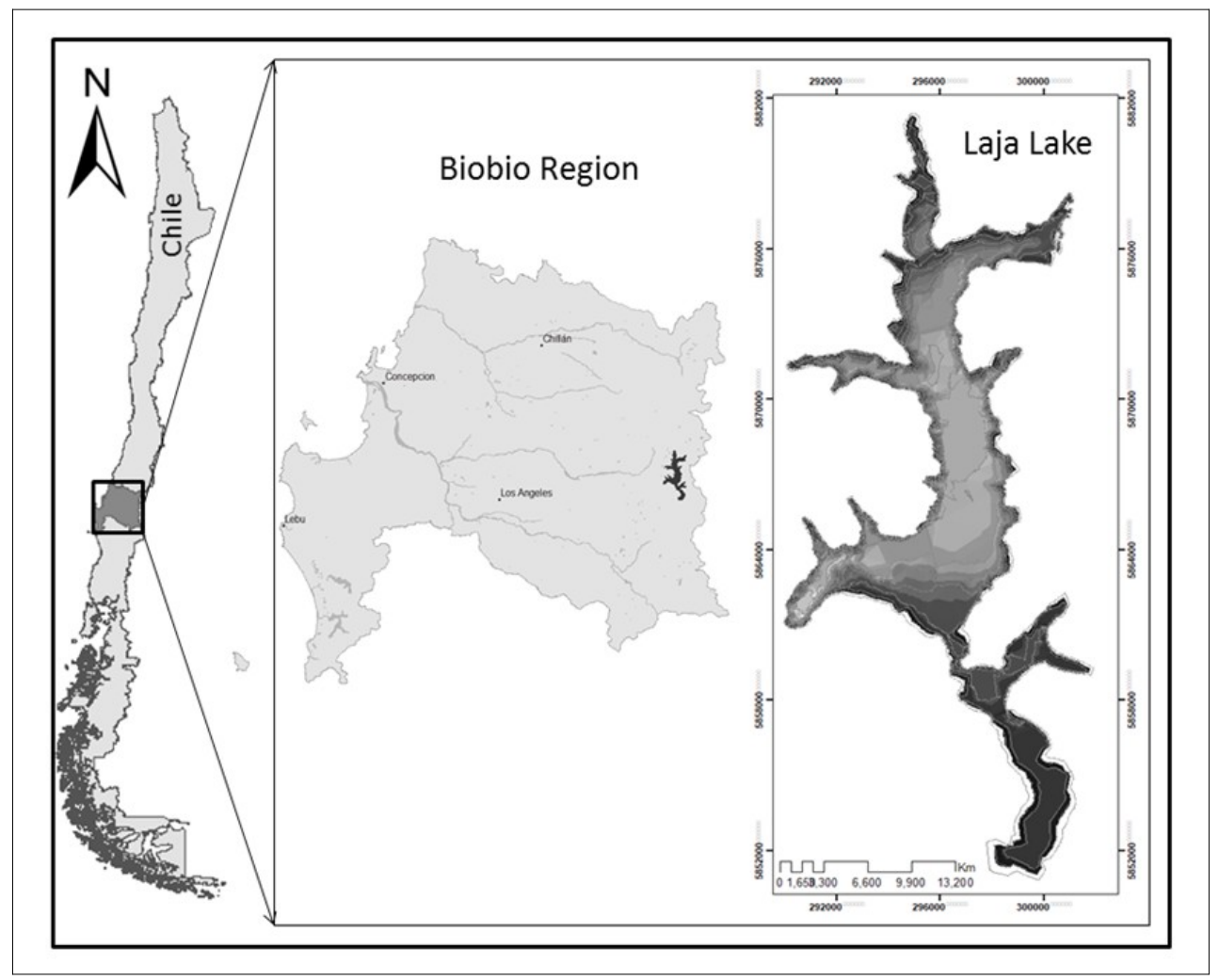

Fig. 1. Study Area.

\subsection{Behavior of Ozone Concentration}

According to its terrestrial distribution, $\mathrm{O}_{3}$ varies over time, with daily or seasonal periods; these variations are caused by the circulation of stratospheric winds and by the production and chemical destruction of $\mathrm{O}_{3}$. It is generally found in lower concentration in Ecuador and in greater abundance in the poles. Due to the special climatic and meteorological conditions in Antarctica, the hole in the ozone layer forms on this site. The difference between the ozone content in the Polar Regions comes from different meteorological patterns [5]. Antarctica is a continent of great extension surrounded by oceans; these symmetrical conditions produce very low stratospheric temperatures. In addition to the global decrease in $\mathrm{O}_{3}$ that affects the entire planet, there is another phenomenon present in the austral spring called $(\mathrm{AOH})$. This phenomenon has a seasonal 
activity, that is to say, it starts its activity at the end of August and continues until the month of December, with annual differences [10].

Chilean territory, because it is very close to this continent, has unique environmental conditions to study how the behavior of this $\mathrm{O}_{3}$ depression affects the latitudes close or near the South Pole. The $\mathrm{O}_{3}$ data was taken from corresponding NASA records available at https://ozoneaq.gsfc.nasa.gov. The values were taken from January 8 to mid-March 2018.

\subsection{Sampling Station}

A monitoring station with two radiation sensors was installed on the shore of the lake. The sensors correspond to an Apogee SQ 500 sensor for measuring photosynthetically active radiation (PAR) in the range of 400 to $700 \mathrm{~nm}$ and an Apogee SU 100 sensor (sensitivity $0.61 \mathrm{mV}$ per $\mathrm{W} \mathrm{m}^{-2}$ ), to measure UV radiation in the range of $280 \mathrm{~nm}$ to 400 $\mathrm{nm}$. The corresponding measurements were considered from 10:00 am to 4:00 pm (segment of the day where the maximum irradiance value is shown). The data were recorded from the months of January to March of 2018, coinciding with the summer season in Chile. The profiles of temperature, dissolved oxygen, $\mathrm{pH}$ and conductivity were recorded with a CTD mark Sea-Bird 19 plus. In order to carry out a comparative analysis of these physicochemical variables in the water column, the information obtained in the monitoring was compiled, for the same period, 2001 [10]. For all analysis of nutrients in 2001: orthophosphate (o-PO4): ascorbic acid method) were determined according to APHA (1998). For the calculation of dissolved inorganic nitrogen (DIN) partly no ammonia values were available (below the detection limit of $7 \mu \mathrm{g} \mathrm{N}-\mathrm{NH} 4$ ). For the analysis of nutrients in 2018 it was used: 4110 B (orto-phosphate), 4500-N-C (Total Nitrogen) and $4500-\mathrm{NH} 3 \mathrm{~F}$ (ammonium) Standard Methods 22th Edition.

\subsection{Optical characteristics of the underwater light field}

Lake Laja presents oligo-trophic conditions, with very transparent waters [14], taking into account this factor and knowing that being a high lake the radiation incident independently of the spectral bands is of great intensity, we would expect the passage of light in the field of underwater light it could affect the microalgae communities that coexist despite the environmental stress conditions that this aquatic body presents as it is subjected to variable temperatures during the day and strong winds. For this, the daily PAR and UV radiation values were measured, as well as a measure of transparency behavior during the days of the monitoring campaign in these months. This measurement was made through the Secchi disk in order to calculate the light attenuation coefficient in the aquatic environment, propose for the first time for this lake an optical classification of its waters, and compare them with classifications established by Jerlov [15] for coastal and oceanic waters.

The light attenuation coefficient (PAR) was calculated through the following formula:

$$
K d=2 / Z(\text { Secchi })
$$

Where Kd is the respective coefficient of attenuation of the light PAR and Z (Secchi) is the average of the Secchi disc transparency.

The attenuation coefficient corresponding to ultraviolet light was calculated through the Lambert Beer law of optics:

$$
E(\lambda, 0)=E(\lambda, 0-) \exp [-K d(\lambda) 0]
$$




\subsection{Algal groups composition}

Quantitative samples were taken with a Niskin sampling bottle and analyzed according to the Utermöhl cell counting method [16] and qualitative phytoplankton samples obtained with phytoplankton net and were analyzed with photon microscopy [17], during the surface level and at different depths $(\mathrm{z}): \mathrm{z}=5,10,15$ and 20 meters, to describe the vertical distribution of the algal groups in the water column and their abundance. In addition, they were compared with samples taken in a campaign in 2001[10] with the same relative depths to assess the variability of phytoplankton communities. Community structures were compared in order to see the evolution of phytoplankton groups and species in the 2001 and 2018 monitoring.

\subsection{Statistics Analysis}

The Shapiro Wilks normality test was run to the time series studied, to check if the ozone concentration, UV radiation and physical- chemical parameters data showed a normal distribution in 2001 and 2018. Since the time series was not distributed normally, Kruskall Wallis test was performed to prove significant differences between the months of the study in 2018. Paired comparisons, using the non-parametric Mann-Whitney U test, were performed to verify the existence of significant differences between the years 2001 and 2018 for the O3, UV and chemical physical parameters of the water column, temperature, dissolved oxygen, $\mathrm{pH}$, Conductivity and Nutrients.

In the case of the biological matrix, community parameters such as species richness, total abundance and Shannon diversity were calculated. Additionally, the relative abundances of the most abundant groups and species found in the water column were determined. All statistical analyzes were performed using R software version 3.5.0 [18] and for biological analyzes, vegan package 2.5.2 [19] was used.

\section{Results and Discussion}

\subsection{Behavior of Ozone Concentration, UV and PAR radiations}

The Figure 2A shows the behavior of the concentration of $\mathrm{O}_{3}(\mathrm{DB})$ during the months of study (January, February and March 2018). During the corresponding summer season, the values were low, in all cases, less than $300 \mathrm{DB}$. The mean values of $\mathrm{O}_{3}$ were $274 \pm 9,16$ DB, $267 \pm 4.61 \mathrm{DB}$ and $259 \pm 14.21 \mathrm{DB}$, for the months of January, February and March, respectively. The maximum concentration of this parameter was 292 DB (January), while the minimum reached was 242 DB (March). Meanwhile, the UV radiation registered mean values that fluctuated between $55.81 \pm 11.72 \mathrm{Wm}^{-2}$ (January) and $68.53 \pm 13.42 \mathrm{Wm}^{-2}$ (February) (Figure 2B). In addition, it was observed that this parameter had an inverse relationship with respect to $\mathrm{O}_{3}$, given that when the ozone concentration was maximum the UV value was minimal and vice versa. The Kruskall Wallis analysis showed hight significant differences in the concentration of $\mathrm{O}_{3}(\mathrm{KW}=26.35, \mathrm{p}<0.001)$ and $\mathrm{UV}(\mathrm{KW}=$ $16.29, \mathrm{p}<0.001)$ radiation between the months of the study.

The PAR and UV radiation values were high during the months corresponding to the summer season in the Southern Hemisphere. However, it was observed that during the last fortnight of March the PAR radiation was more variable and tended to decrease, registering values lower than $100 \mathrm{Wm}^{-2}$ (Figure $2 \mathrm{C}$ ). The maximum values of PAR radiation were 
recorded between 10 o'clock in the morning and 2 o'clock in the afternoon. The monthly average of the PAR radiation oscillated between $295.88 \pm 37.53 \mathrm{Wm}^{-2}$ (March) and $401 \pm$ $42.34 \mathrm{Wm}^{-2}$ (January).

The comparison in the behavior of the concentration of $\mathrm{O}_{3}$ between 2001 and 2018, showed that during the summer of 2001, there was less variability and the average monthly values of this gas (January $=284.10 \pm 4.67 \mathrm{DB}$, February $=283.89 \pm 4.69 \mathrm{DB}$, March $=$ $287.10 \pm 3.10 \mathrm{DB}$ ) were higher than those registered in 2018 (January $=273.39 \pm 9.16 \mathrm{DB}$, February $=266.82 \pm 4.61 \mathrm{DB}$, March $=258.77 \pm 14.21 \mathrm{DB}$ ) (Figure $3 \mathrm{~A}$ ). While UV radiation, showed an inverse behavior, presenting higher and more variable monthly mean values in 2018 (January $=57.06 \pm 11.72 \mathrm{Wm}^{-2}$, February $=69.79 \pm 13.42 \mathrm{Wm}^{-2}$, March $=$ $\left.65.69 \pm 7.59 \mathrm{Wm}^{-2}\right)$ compared to year $2001\left(\right.$ January $=19.64 \pm 3.37 \mathrm{Wm}^{-2}$, February $=$ $19.47 \pm 2.34 \mathrm{Wm}^{-2}$, March $=14.31 \pm 3.43 \mathrm{Wm}^{-2}$ ) (Figure $3 \mathrm{~b}$ ). All paired comparisons between the months of study, for the concentration of $\mathrm{O}_{3}$ and $\mathrm{UV}$, were highly significant $(\mathrm{p}<0.001)$.

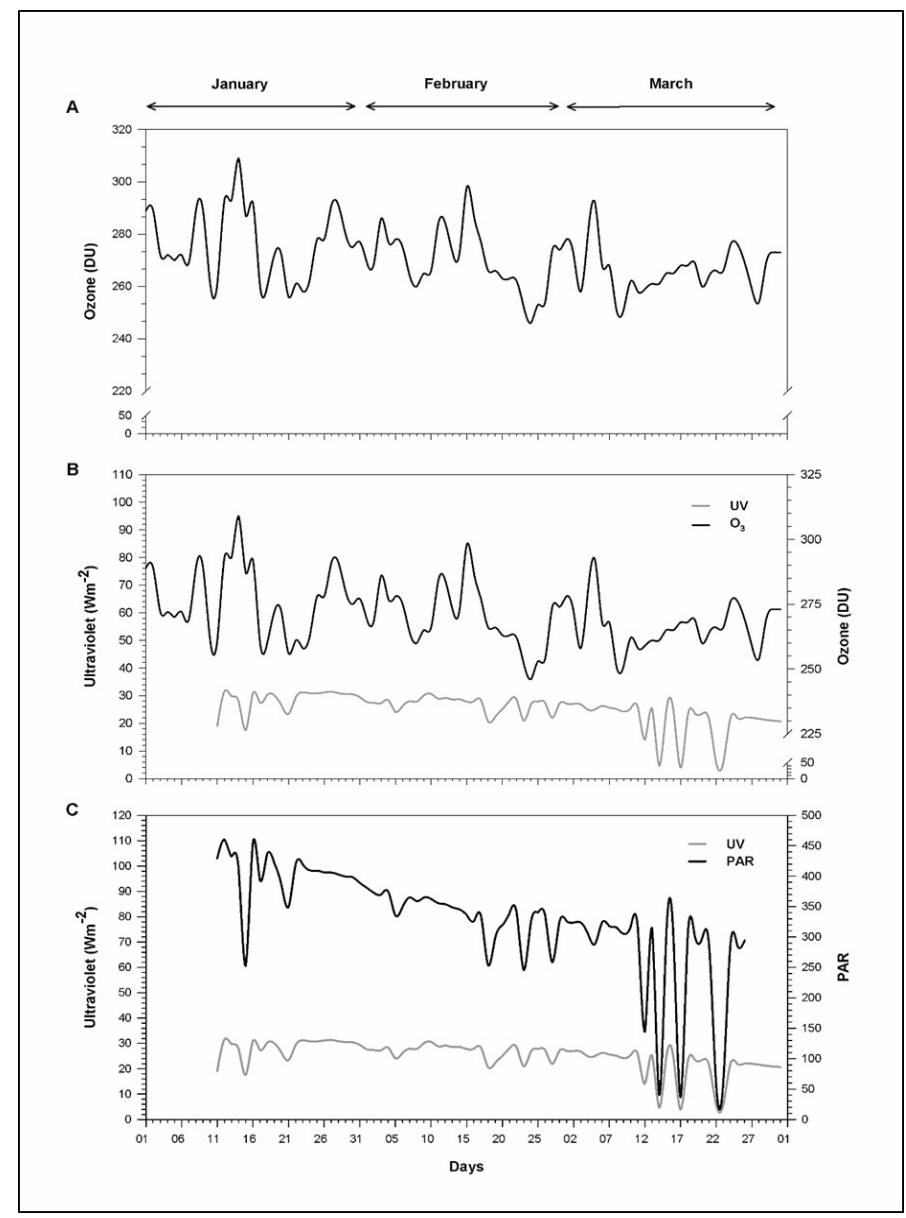

Fig. 2. Behavior of Ozone Concentration, relation between UV vs $\mathrm{O}_{3}$ and PAR vs UV. 


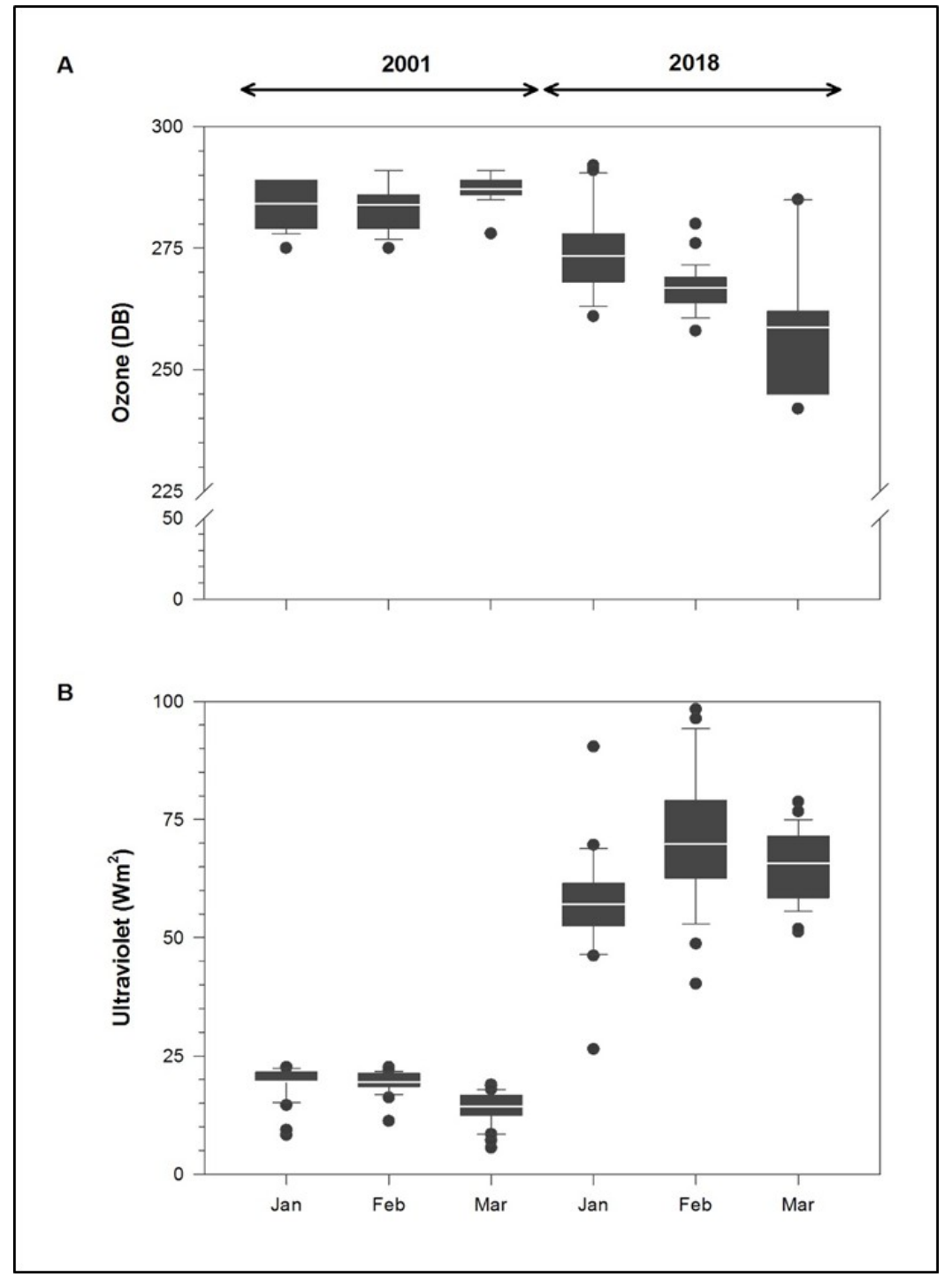

Fig. 3. Concentration of $\mathrm{O}_{3}$ (A) and UV radiation (B) between the summer months of the years 2001 and 2018. The white line represents the mean value.

\subsection{Optical characteristics of the aquatic environment}

The values of transparency were $4.0 \mathrm{~m}$ in January and $7.5 \mathrm{~m}$ in March of 2018, allowing obtaining attenuation coefficients $(\mathrm{Kd})$ for the photosynthetically active radiation of 0.50 and 0.27 , while for ultraviolet radiation were 1.02 and 1.01 during January and March of 2018, respectively.

The values of the coefficient of attenuation of the PAR and UV light for the study period (summer season) reflect that the Laja lake has a corresponding propagation coefficient, as type I (clear, transparent waters); according to Jerlov's classification of ocean waters (Figure 4). 


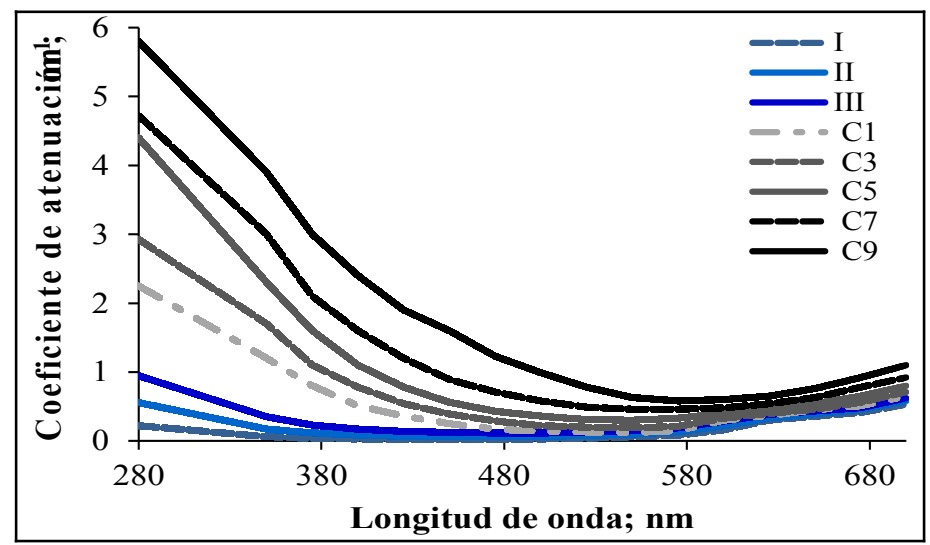

Fig . 4. Jerlov classification of ocean and coastal waters.

\subsection{Chemical physical parameters of the water column}

The vertical behavior $(0-40 \mathrm{~m})$ of the physical and chemical parameters of the water column, between March 2001 and 2018, showed that the average values of $\mathrm{pH}$ and conductivity tended to increase $(\mathrm{pH} 2001=7.74 \pm 0.13, \mathrm{pH} 2018=8.93 \pm 0.29$, Cond $2001=$ $16.10 \pm 5.04 \mu \mathrm{S} / \mathrm{cm}$, Cond2018 $=46.30 \pm 1.30 \mu \mathrm{S} / \mathrm{cm}$ ), while dissolved oxygen decreased $(\mathrm{OD} 2001=8.25 \pm 0.69 \mathrm{mg} / \mathrm{L}, \mathrm{OD} 2018=6.08 \pm 0.28 \mathrm{mg} / \mathrm{L})$. However, the temperature did not show differences in their mean values (March2001 $=10.88 \pm 4.62{ }^{\circ} \mathrm{C}$, March2018 $\left.=10.66 \pm 1.07^{\circ} \mathrm{C}\right)$. The U-Mann Whitney test showed that the parameters dissolved oxygen, $\mathrm{pH}$ and conductivity were highly significant between March 2001 and 2018 ( $p<0.001$ ) (Figure 5). In both periods, the concentration of orthophosphate was $\leq 0.04$ $\mathrm{mg} / \mathrm{L}$, while the total nitrogen ranged between 0.10 and $0.21 \mathrm{mg} / \mathrm{L}$. During the period analyzed, the nutrients in the lake have not varied significantly.

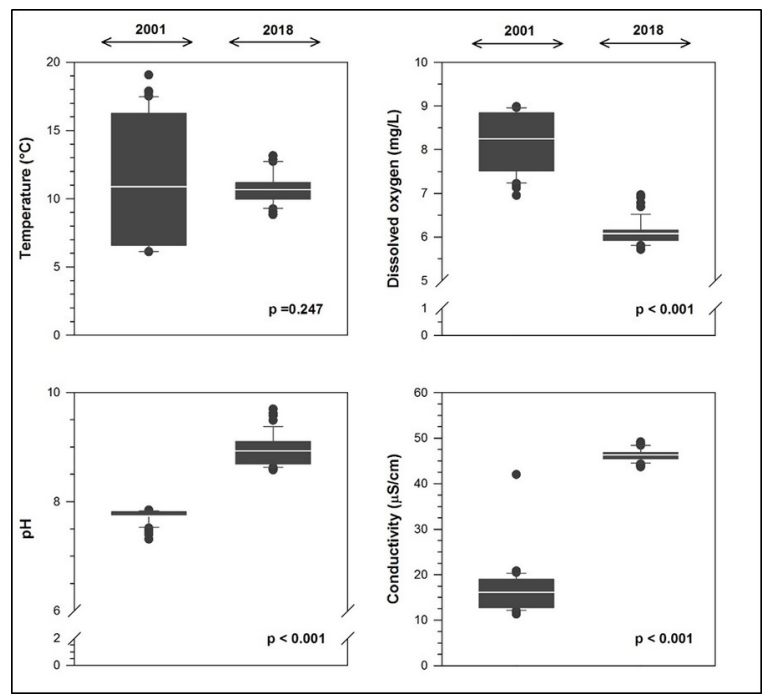

Fig. 5. Chemical physical parameters of the water column $(0-40 \mathrm{~m})$ recorded in March 2001 and 2018. The white line represents the average values. 


\subsection{Algal community}

The algal community of Lake Laja was composed of 29 species of 6 different class (Bacillariophyceae, Mediophyceae, Cyanophyceae, Chrysophyceae, Dinophyceae, Cryptophyceae, Conjugatophyceae (Zygnematophyceae)). It was observed that the media values of species richness, abundance and Shannon diversity were higher in January than March (Figure 6A). The Figure 6B shows the relative abundance of the main groups, with the Bacillariophyceae group dominating in January and with a marked increase $(>50 \%)$ in the Cyanobacteria group in March. The species that contributed most to the abundance in January were Fragilaria crotonensis (54.46\%), Dolichospermum circinale (16.53\%), Cyclotella ocelata (15.96\%) and Asterionella formosa (11.97\%), while in March 2018 dominated mainly that cyanobacteria Dolichospermum circinale $(73.84 \%)$ following by Fragilaria crotonensis $(19.03 \%)$ (Figure 6C). The comparison the different groups and species between 2001 and 2018 shows in (Figure 7).

In March 2001 there was a greater variability of groups and species in the algal communities of Lake Laja, with the Chlorophyceae (52\%) followed Bacillariophycea $(39,43 \%)$ group dominating the community, while in 2018 the dominant group was the Cyanophyceae and dis not presence of (Chlorophyceae).

In relation to the taxonomic composition it was observed that there was a change in the richness and dominance of the species. In 2001 domino S. schoeteri (50.94\%) followed by F. crotonensis $(21.56 \%)$ while in 2018 domino D. circinale $(73.8 \%)$.

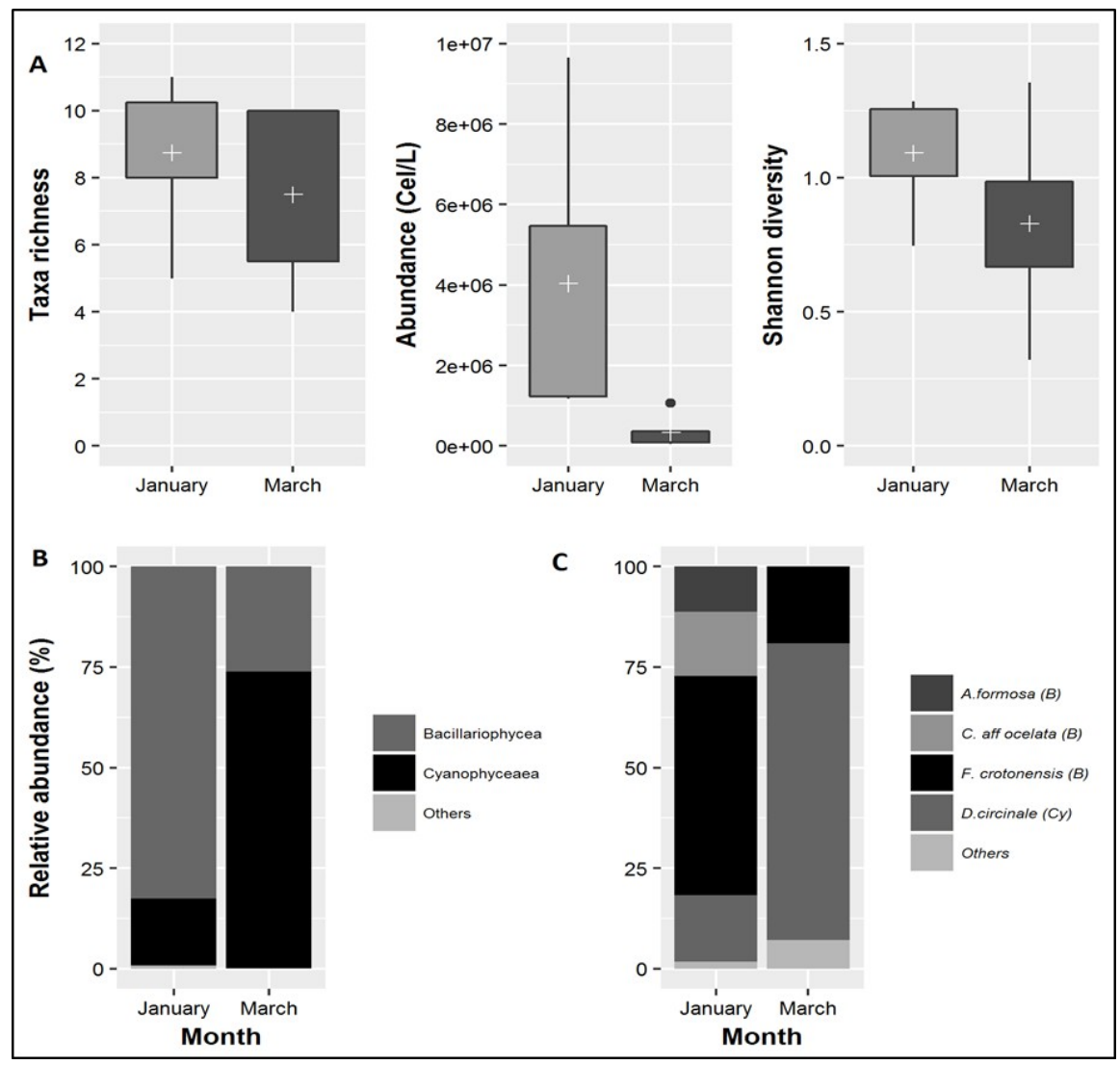

Fig. 6. Relative abundance main groups and species in Laja Lake in 2018. 


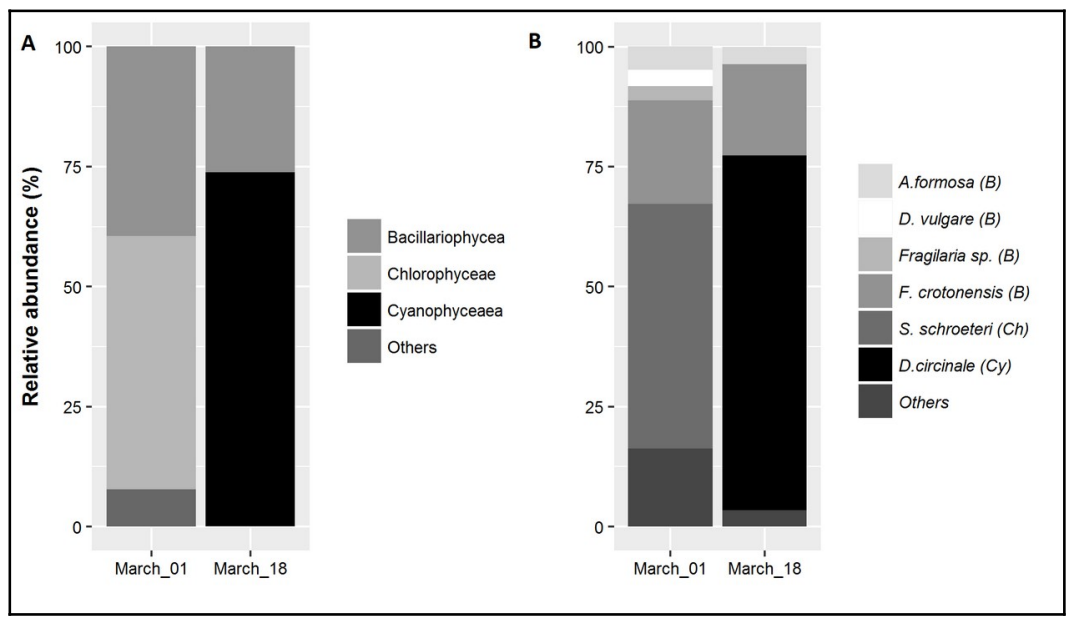

Fig. 7. Comparisons between main groups and species in 2001 and 2018.

\section{Discussion}

In the summer season corresponding to the year 2018, in the Southern Hemisphere low concentrations of $\mathrm{O}_{3}$ were reported (lower than $250 \mathrm{DB}$ ), which generated high levels of UV and PAR radiation in the study area during the monitoring campaign. In this respect, values considered as extremely high UV radiation $\left(>50 \mathrm{~W} \mathrm{~m}^{-2}\right)$ were obtained, which has been reported by other authors [7] [5], as a cause of damage in aquatic organisms. In this context, the damage in the aquatic communities can also manifest itself in this study area, favored by the altitude (1360 m.a.s.l.) and the classification of its waters (Type I), where the passage of light through the field of light underwater benefits by the clarity or transparency of its waters.

During the monitoring in January 2018, a bloom of Dolichospermum circinale [20] it was detected for the first time in this lake, mainly between 0 and $5 \mathrm{~m}$ deep, it is necessary to keep in mind that it is characteristic of this algal group to form blooms at a superficial level [21]. These blooms are extremely unusual, since it is thought that low concentrations nutrient limit bloom in oligotrophic systems [22][23], and these also depends on light and temperature [24] [25]. According to Lambert Beer law optics can be obtained that between 2 and $5 \mathrm{~m}$ depth there is $40 \%$ more light than below this level of depth [26] and cyanobacteria are highly dependent on high intensity light for nitrogen fixation [27]. Previously, this lake was described as a lacustrine system limited by nitrogen [10], however, this species of cyanobacteria has the ability to fix nitrogen from the atmosphere [21]. In relation to the concentration of nutrients, the levels did not register an important variation (remaining the o-PO4 $\leq 0.04 \mathrm{mg} / \mathrm{l}$ and the total nitrogen registers concentrations between 0.10 and $0.21 \mathrm{mg} / \mathrm{l}$ ). This suggests that the radiative variability, especially of the $\mathrm{UV}$, may be playing a decisive role in the appearance of blooms of certain cyanobacteria.

The current conditions of the lake laja show an increase in the levels of UV radiation it receives at surface level, the altitude at which it is exposed this lake to changing climatic variables in short periods of time, its optical characteristics of transparent waters due to its oligotrophy state that allow more easily the transmission of light in the underwater field have allowed an increase in the last two decades of the group of the cyanobacteria and their dominance due to the ecological advantages that they present with respect to the other algal groups because they are better adapted to the new conditions that prevail in this lake and that have generated a flowering that has persisted throughout the study period. These 
blooms have been reported by other authors in oligotrophic systems [28][22]. The importance of this study lies in the fact that continental aquatic systems, like this Lago Laja, due to its oligotrophic characteristics and absence of contamination, represent lakes systems a high environmental value due to the multiple uses of their waters, for which it will be necessary to pay attention if these blooms show toxicity which could mean a limitation in the use of this resource.

\section{Conclusions}

The results showed low levels in the $\mathrm{O}_{3}$ concentration during the whole study period (summer 2018), while the values of UV and PAR radiation were quite high, showing the maximum values of UV radiation in the month of February (above $50 \mathrm{Wm}^{-2}$ ). All paired comparisons between the months of study, for the concentration of $\mathrm{O}_{3}$ and $\mathrm{UV}$, were highly significant ( $\mathrm{p}<0.001)$. An optical classification of this lake ecosystem is proposed as type I waters (very clear), comparing the attenuation coefficients of the photosynthetically active and ultraviolet radiation according to the Jerlov's classification. For the first time, was found in this freshwater ecosystem, one toxic algae bloom species corresponding to the species Dolichospermum Circinale (Cyanobacteria), probably caused by the variability in the levels of UV reaching lake's surface.

Lien Rodríguez López and Lisdelys González thank the National Scientific and Technological Commission (CONICYT). Roberto Urrutia and Oscar Parra thank the Center for Water Resources for Agriculture and Mining CRHIAM / CONICYT / FONDAP / 15130015. Bernhard Karrasch thanks UFZ - Helmholtz Center for Environmental Research, Brückstraße 3a, D-39114 Magdeburg, Germany.

\section{References}

1. J. Rockström, W. Steffen, K. Noone, Å. Persson, F.S. Chapin, E. Lambin, T.M. Lenton, M. Scheffer, C. Folke, H.J. Schellnhuber, B. Nykvist, C.A. de Wit, T. Hughes, S. van der Leeuw, H. Rodhe, S. Sörlin, P.K. Snyder, R. Costanza, U. Svedin, M. Falkenmark, L. Karlberg, R.W. Corell, V.J. Fabry, J. Hansen, B. Walker, D. Liverman, K. Richardson, P. Crutzen, J. Foley, Ecol. Soc. 14 (2009)

2. W.T. Ball, J. Alsing, D.J. Mortlock, J. Staehelin, J.D. Haigh, T. Peter, F. Tummon, R. Stübi, A. Stenke, J. Anderson, A. Bourassa, S.M. Davis, 1379-1394 (2018)

3. S. Agustí, M. Llabrés, B. Carreja, M. Fernández, C.M. Duarte, Contrasting Sensitivity of Marine Biota to UV-B .Estuaries and Coasts. 38, 1126-1133 (2015)

4. L. Cornejo, L. Martín-Pomares, D. Alarcon, J. Blanco, J. Polo, Chile, Renew. Energy. 112, 197-208 (2017)

5. S. Agustí, Impacto Del Calentamiento Glob. Sobre Los Ecosistemas Polares, 25-46 (2007)

6. J.J. Fritz, P.J. Neale, R.F. Davis, J.A. Peloquin, Mar. Ecol. Prog. Ser. 365, 1-16 (2008).

7. S. Leech, D. M., \& Johnsen (2003)

8. S.R.\& M.P.-B. Thiele R, Moreno, S. Elgueta, A. Lahsen, Thiele, R, Rev. Geológica Chile. 25 (2), 229-253 (1998)

9. F. Cruces, Universidad de Concepcion, Universidad de Concepcion (2006)

10. C. Valdovinos, H. Cid, O. Parra, Rev. Chil. Hist. Nat. 84, 433-450 (2011) 
11. Cleve \& Möller ( Bacillariophyceae ) Gyna 67, 12-18 (2010)

12. M. Nacional, H. Natural, 95, 89-95 (1991)

13. P. Pedreros, 2007 Limnologica (2016)

14. C. Valdovinos, C. Moya, V. Olmos, O. Parra, B. Karrasch, O. Buettner, Biodivers. Conserv. 16, 3095-3109 (2007)

15. Jerlov, N.G., Marine Opt, Elsevier Scientific Publishing Company, Amsterdam (1976)

16. H. Utermöhl, Uthemol, Mitteilung, Germany (1958)

17. O. Parra, Gayana (Concepción). 70, 8-15 (2006)

18. R Core Team, R., https://www.r-project.org/ (2017)

19. J. Oksanen, F.G. Blanchet, M. Friendly, R. Kindt, P. Legendre, D. Mcglinn, P.R. Minchin, R.B. O'hara, G.L. Simpson, P. Solymos, M. Henry, H. Stevens, E. Szoecs, H. Wagner, M.J. Oksanen, Package "vegan,”. https://github.com/vegandevs/vegan/issues (2018)

20. J. Ralph, The annals, Mag. Histoey, Natueal. 29 (1878)

21. W. Pirjo, H. Lucien, K. Jiř́́, comb . nova, 9, 59-64 (2009)

22. C.C. Carey, K.C. Weathers, K.L. Cottingham, Plankton research, 30 (8), 893-904 (2008)

23. E. Downing, J. A., Watson, S. B., \& McCauley,. Aquat. Sci. 58, 1905-1908 (2001)

24. R.P. Barbiero, Arch. Fur Hydrobiol. 127, 87-100 (1993)

25. I. Karlsson, Hydrobiology. 506, 189-193 (2003)

26. R. Wetzel, Limnology: lake and river ecosystems, gulf professional publishing (2001)

27. T.P. Chang, Br. Phycol. J. 14, 207-210 (1979)

28. J. Nimptsch, S. Woelfl, S. Osorio, J. Valenzuela, C. Moreira, V. Ramos, R. CasteloBranco, P.N. Leão, V. Vasconcelos, Int. Rev. Hydrobiol. 101, 57-68 (2016) 